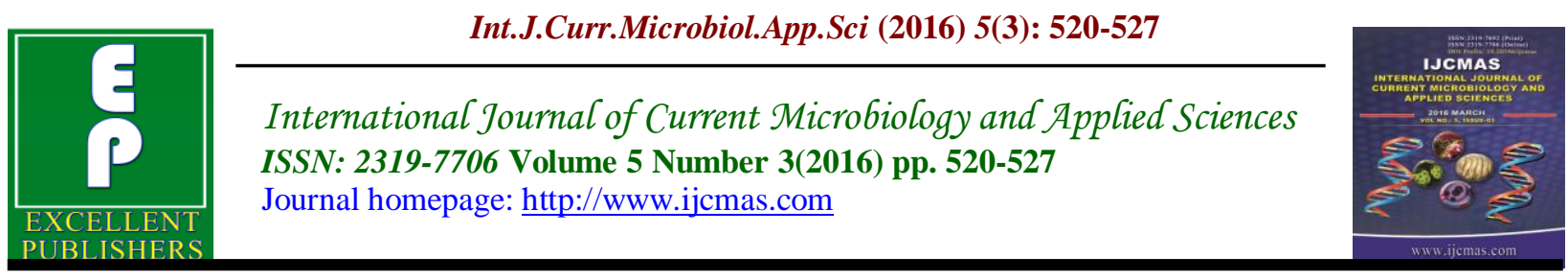

Original Research Article http://dx.doi.org/10.20546/ijcmas.2016.503.061

\title{
A Study on Wood-Decaying Fungi from the Forests of Western Maharashtra, India
}

\author{
Mulchand M. Rathod* \\ S.S.M.M. Arts, Science and Commerce College, Pachora - 424 201, \\ Jalgaon, Maharashtra, India \\ *Corresponding author
}

Keywords

Wood decaying polypores, Western Maharashtra, Basidiomycetes, White rot, Brown rot, Daedalea africana and Daedalea quercina

Article Info

Accepted:

18 February 2016

Available Online:

10, March 2016

\section{A B S T R A C T}

Wood-decaying polypores, referring to basidiomycetes having the capacity to decompose lignocelluloses, which decompose forest wastes and coarse woody debris (fallen trunks, branches, stumps etc.) are essential for the functioning of forest ecosystems. For the present study, from different sites of forests of Western Maharashtra, sixty five specimens, especially polypore fungi were collected and critically examined with respect to their macro and micro morphological characters, cultural behavior and enzyme tests. On the basis of the observations fifteen species of wood decaying polypores are identified. Out of the fifteen species of wood decaying polypores observed in the study area, two species of brown rot i.e. Daedalea africana and Daedalea quercina are described in the present paper. The specimens were characterised using microscopic and macroscopic parameters and chemical tests. Cultural study was made and cultural characteristics are described. Freehand sketches of the fungal forms and Camera-Lucida drawings are also given.

\section{Introduction}

Wood decomposition is a decisive process in nutrient recycling, soil formation and the carbon budget of forest ecosystems (Lonsdale et al. 2008). It is an essential functional component of all ecosystems with two main significant aspects. First, it is the principal process whereby essential nutrient elements are made available to the primary producers and secondly decomposition process plays a major part in the formation of humus molecules.
Forest wastes and agricultural materials containing high levels of lignocelluloses are particularly abundant in nature and have potential for bioconversion. They constitute the renewable resource from which many useful biological and chemical products can be derived. Accumulation of this biomass in large quantities every year results not only in deterioration of the environment but also in loss of potentially valuable materials that can be processed to yield energy, food and chemicals. In decomposition process wooddecaying polypores, referring to 
basidiomycetes, which have capacity to decompose lignocelluloses play very important role. Therefore the biology of wood - decaying basidiomycetes drawn attention from scientists in several different disciplines such as forest ecology (Lonsdale et al. 2008), Forest pathology (Asiebu et al. 2005, Ofodile et al. 2010), Biotechnology (Cohen et al. 2002) and Bioremediation (Kaushik et al. 2009) etc.

The fungus, mostly basidiomycetes are the most efficient lignin degraders in nature (Eriksson et al., 1990). Polypores are the wood decaying fungi that attack on wood and play a major role in the processes of its decay. Numerous species are lignicolous and grow on bark or wood.

Two kinds of wood decay are distinguished; one the white rot, where lignin is degraded and cellulose is partially degraded and thus wood is bleached, and Second the brown rot where cellulose is degraded and lignin is left as a brown residue. The ability of white-rot and brown-rot fungi to degrade all principal components of wood is important for carbon flux in ecosystems (Leonowiez et al., 1999; Baldrian and Gabriel 2003).

With this extra ordinary capacity of degrading cellulose, these fungi have wide range of applications. The main potential applications are in food, animal feed, textile, fuel, detergents and chemical industries, while other eco-friendly applications include those in the environment waste management and in developing environmentally safe technologies for paper and pulp industries. Considering all these important aspects of the Wood-decaying polypores, the two forms Daedalea africana and Daedalea quercina are selected for the present study.

\section{Materials and Methods}

For present investigation specimens (fruiting bodies) of Daedalea where collected from different sites of the Western Ghats and Satpura ranges, in the state of Maharashtra (Figure.1). The specimens where conveniently collected in the paper bags, noting the host, locality, colour of the material and date of the collection as suggested by Gilbertson and Ryvarden (1986).

From the collection few specimens were used for spore prints, sporocarp culture and a few for macro and micro morphological characters of the basidiocarp. Micro structure has been studied from the sections of fruiting body. Martin's (1934) staining method was used. Lactoglycerin with $1 \%$ cotton blue were used for semi-permanent slides, which were sealed with a nail polish (Beneke, 1958). Melzers reagent (IKI) prepared as per the method of Singer (1982) was used for testing the amyloidity and dextrinoidity.

Sporocarp culture was obtained by aseptically transferring a piece of fruiting bodies into to the sterile 2\% Malt Extract Agar (MEA) medium containing $10 \mathrm{ppm}$ Novobiocin and incubated at $25^{\circ} \mathrm{c}$ for $4-6$ weeks in B.O.D. Isolates were sub cultured and transferred to the fresh slant for every fortnight. The pure cultures were obtained and stored on $2 \%$ MEA slant.

Culture characteristics of the specimens were described using the terminology of Rayner (1975) and Stalpers (1978), on the basis of characters such as chemical tests for detection of enzymes; growth rate; characteristics of mat; other macroscopic characters; hyphal characters; propagative structures etc. The species were identified with their species code on the basis of a key proposed by Stalpers (1978).

The type of rot was identified by spraying $1 \%$ benzidine solution in $90 \%$ ethanol 
(Hintikka, 1970), on decaying wood sample. Oxidase reactions in cultures were determined by growing fungi on malt agar medium containing Gallic acid and Tannic acid separately. (Gilbertson and Ryvarden, 1986).

\section{Results and Discussion}

Specimens collected from different sites were critically examined with respect to their external and internal Morphological characters of basidiocarp, cultural behaviour and enzyme tests. The observations of the study are as follows,

\section{Descriptions of Taxonomy, Morphological and Cultural Characters}

Daedalea africana Johan \&Ryv. apudRyv. \& Johan A Prel. Poly Fl. East Africa,304, 1980

\section{Morphological Characters:(Figure.2)}

Fruitbody Perennial, solitary, pileate, broadly to narrowly attached like a small stipe, woody hard when dry 8-14 cm long $\mathrm{x}$ $8-9 \mathrm{~cm}$ wide x 0.5-1.5 $\mathrm{cm}$ thick; Pileus: dimidiate to semicircular to planate, dull, flat or slightly convex, upper surface first slightly tomentose and light greyish brown, latter more glabrous and dark fulvous or greyish bay, very old specimens dark fulvous brown, very strongly concentrically zonate,sulcate especially near margin, completely covered by small irregular warts and ridges, margin rather thick, entire or slightly lobed; Pore surface:dull to light grey, yellowish white in young specimen, light brown to fulvous in mature hymenial layer poroid to daedaleaoid to labryinthioid, later marginal lamellate, mostly, typically daedaleaoid pores $2-3 \mathrm{~mm}$ in diameter, pore wall $1 \mathrm{~mm}$ thick; pore tube $2-4 \mathrm{~cm}$ long, 10 12 lamellae per $\mathrm{cm}$. cream to light grey to brown but always with greyish tint, $3.5 \mathrm{~mm}$ thick.

Hyphal System Trimitic, Generative hyphae hyaline, thin to slightly thick walled, branched, clamped 2.5-3.5 $\mu \mathrm{m}$ in diameter; Skeletal hyphae dominant, light ochraceous brown to yellow, thick walled unbranched, aseptate 2.5 to $5.5 \mu \mathrm{m}$ in diameter; Binding hyphae yellowish brown, slightly thick walled solid to subsolid, tortuous with short stout branches 2-3 $\mu \mathrm{m}$ in diameter; Cystidia:absent, tips of vegetative hyphae project into hymenium; Hyphalpegs: present, conical to cylindrical in shape, Basidia: clavate, four sterigmate 14.1-16.4 x $4.1 \mu \mathrm{m}$; Basidiospores: broadly ellipsoidal oblong to cylindrical, hyaline, smooth and non-amyloid 4-6 x $2.3 \mu \mathrm{m}$ (L/B 1.7-2.6 (2.1))Habitat: on dead wood of Angiosperm.

\section{Chemical Test}

Benzidine test negative, Brown rot on dead wood.

\section{Distribution}

Cosmopolitan species common in Asia, Europe, Poland, North, Central Asia, North America and North Africa.Two specimens collected from karnala; RPO-10 and RPO26 on Mangiferaindicaland Pongmiaglabra and one speciesRPO-37 from Toranmal on Terminaliatomentosa.

Culture Characters: (Figure.2 and Figure. 3)

\section{Growth Characters}

Growth moderate $40-60 \mathrm{~mm}$ in two weeks, Entireplate covered in two weeks; Advancing zone white, even appressed to raised, hyphae dense and rather distinct; Mat white, margin becoming cottony to woolly, finally dense woolly to floccose, crustose 
area developed; Colony white to pale yellow; Reverse bleached showing zones on lower surface; odour none.

Tests for Extracellular Oxidases-are negative on Gallic acid and tannic acid agars, diffusion zones were none for $\alpha-$ napthol \& guaical, syringaldazine reactions were negative.

Hyphalcharacters- Advancing zone hyphae hyaline thin walled, much branched; simple septet with clamps 1.5-3.5 $\mu \mathrm{m}$ in diameter; Aerial hyphae hyaline to pale yellow coloured, slightly thick walled, much branched 3-5 $\mu \mathrm{m}$ diameter; Submerged hyphae thick walled, shortly branched forming cuticle; Mycelium pale yellow, thin walled branched simple clamped septet 2-3 $\mu \mathrm{m}$ in diameter, some are forming intercalary to terminal swellings, which are thick walled 6.4-12.9 x 5.8-8.2 $\mu$ msometimes later irregular swellings are observed. Interlocking hyphae observed chlamydospores are present, up to $7.2 \times 5.2$ $\mu \mathrm{m}$ in dimension.

\section{Speciescode}

$3,5,7,13,15,19,21,22,30,37,39,45,47,48,53,5$ $4,63,64,75,85,88,89$.

Remarks- The species is recorded for the first time from India and has affinity with East African polypores. Presence of chlamydospores and intercalary swellings inculture indicates its close affinity to its type species (D.quercina Fr.). The culture characters of the species are described for the first time.

\section{Daedalea quercina Fr.}

Syst. Mycol. 1 : 333, 1821

\section{Morphological Characters: (Figure. 4)}

Fruitbody: perennial single or few specimens fused laterally broadly sessile to dimidiate, more rarely effused reflexed to effused, sometimes imbricate to semicircular, corky to woody hard, strongly attached to the surface $10-15 \mathrm{~cm}$ long $\mathrm{x}$ 7$10 \mathrm{~cm}$ wide x $3-5 \mathrm{~cm}$ thick; Pileus:semicircular more or less ungulate, flat to slightly convex, uneven, smooth to finely velutinate, concentrically zonate, sometime indistinctly zonate, sulcate especially near the margin, some specimens with tufts of raised hyphae or scattered nodules or warts, the base more rough than the margin which is usually smooth, ochraceous to wood coloured at margin, inner part deeper brownish to greyish in old specimens, sometimes with pads or smaller areas with fresh outgrowth of light ochraceous mycelium, margin sharp, wavy either blunt or thin, wood or leather yellow coloured; pore surface: Flat to oblique especially close to the substrate, hymenophore irregular, along the margin elongated poroid, mostly hymenophore consists of either rounded angular pores later elongate from 1-2.5 mm diameters in the inner parts with sinuous pores or typically daedaloid, split in front pale yellow to wood coloured, mostly ochraceous, pores 1-2.5 $\mathrm{mm}$ in diameter, pore wall 1-2 mm thick, pore tubes up to 2-3 $\mathrm{cm}$ long. 6-7 lamellae per cm, inner walls of pores white coloured trama, distinctly darker; Context:ochraceous to tobacco brown, with distinct annual zones, up to 1 cm thick.

Hyphalsystem - trimitic; generative hyphae hyaline, thin walled, septet with clamps at the septa, 1.5-3.7 $\mu \mathrm{m}$ in diameter, Skeletal hyphae dominating in the fruit body, thick walled to sub solid or solid, unbranched, aseptate 5-6 $\mu \mathrm{m}$ in diameter; Binding hyphae light golden to yellowish brown, thick walled to solid, tortuous with short branches 2.3-4.1 $\mu \mathrm{m}$ in diameter; Cystidia: absent but both binding and skeletal hyphae 
may project into the hymenium and develop a catahymenium; Hyphalpegs: present, conical in shape Basidia:clavate, four sterigmat, $\quad 10.5-15.2 \quad \mathrm{x} 4.7-5.8 \quad \mu \mathrm{m}$ basidiospores: ellipsolid to cylindrical on one side slightly flattened at the base hyaline, thin walled smooth and nonamyloid 6.1-8 x 2.5-3 $\mu \mathrm{m}$ (L/B 2.4-2.6 (2.5)).

Figure.1 Map of Maharashtra Showing Collection Spots

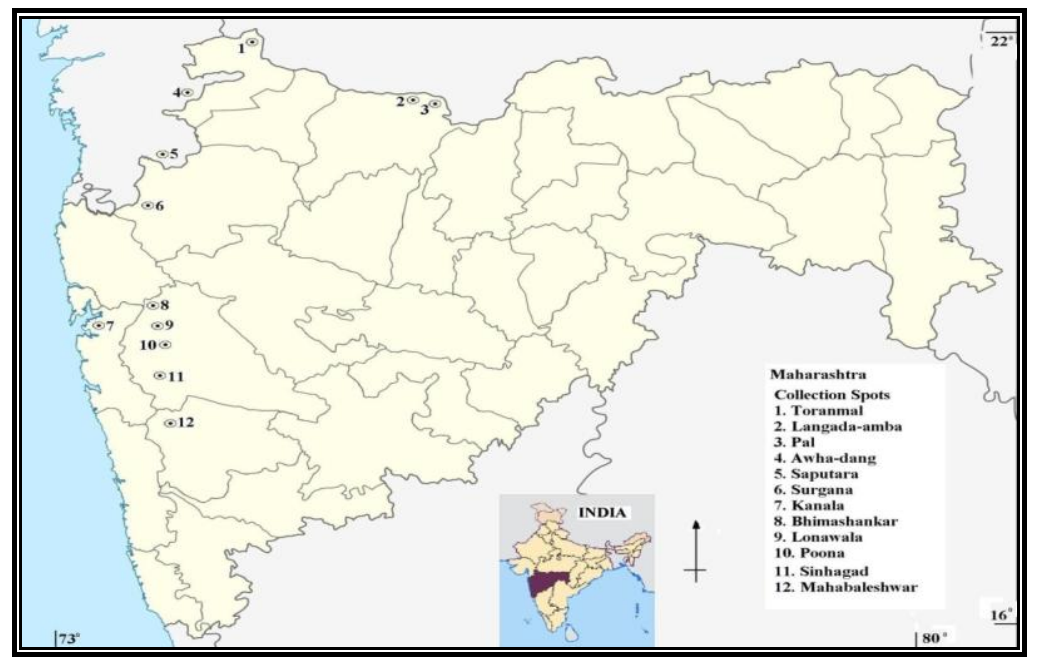

Figure.2 Daedalea africana

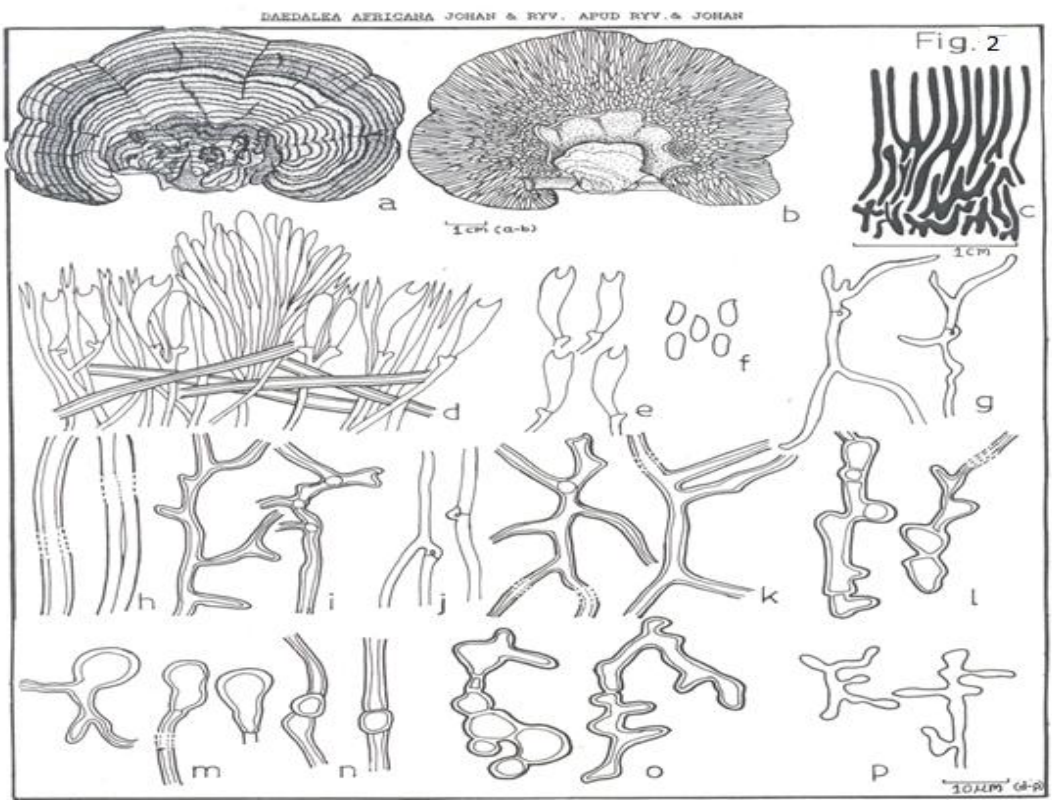

a. Upper surface b. Lower surface c. Nature and number of pores per cm.d. Hymenium e. Basidia f. Basidiosporesg.Generative hyphaeh.Skeletal hyphaei.Binding hyphae Generative hyphae in culture.K. Aerial hyphae in culturel.Submerged hyphae in culturem.Swellings (in culture)n.Chlamydospores in cultureo. Interlocking hyphae in culturep.Cuticular hyphae in culture 
Figure.3a Upper and b. Lower Surface of the Culture Plate of Daedalea africana
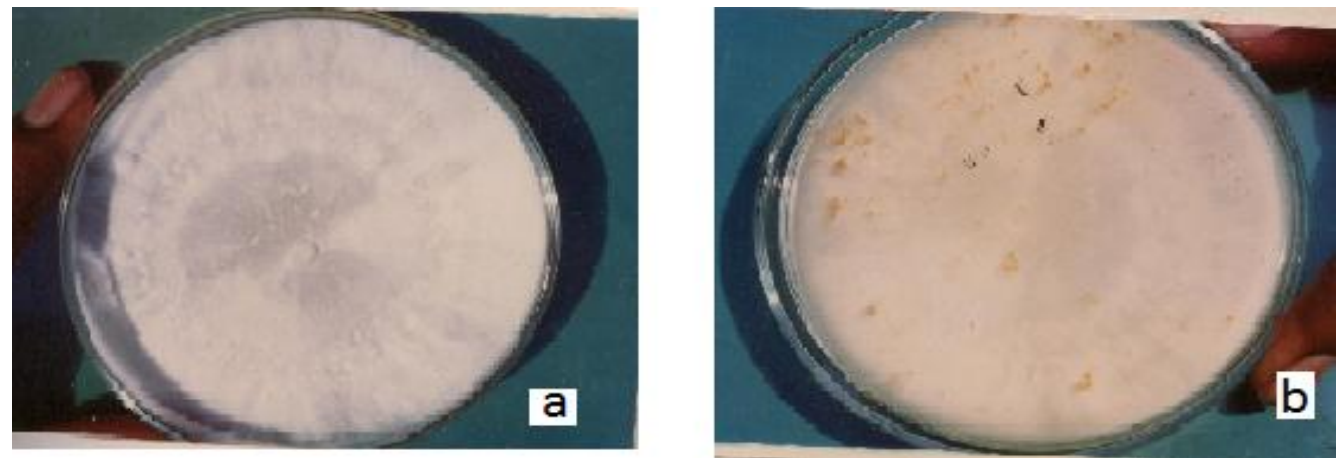

Figure.4 Daedalea quercina

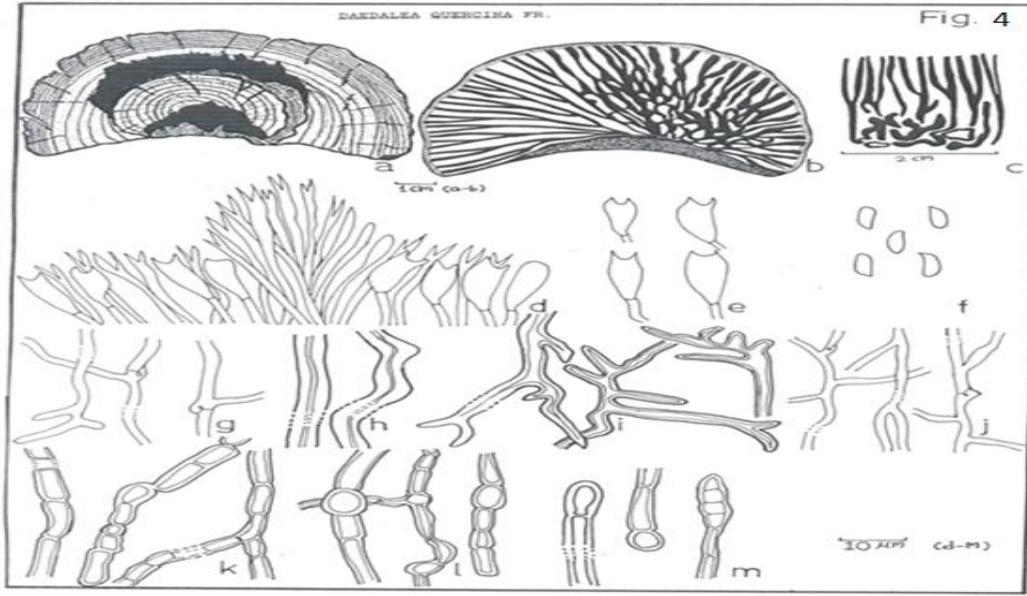

a.Upper surfaceb.Lower surfacec.Nature and number of pores per cm.d.Hymenium e.Basidiaf.Basidiosporesg.Generative hyphaeh.Skeletal hyphaei.Binding hyphae j.Generative hyphae in culture.K.Aerial mycelium in culturel.Chlamydospores in culturem.Swellings (in culture)

Figure.5a Upper and b. Lower Surface of the Culture Plate of Daedalea quercina
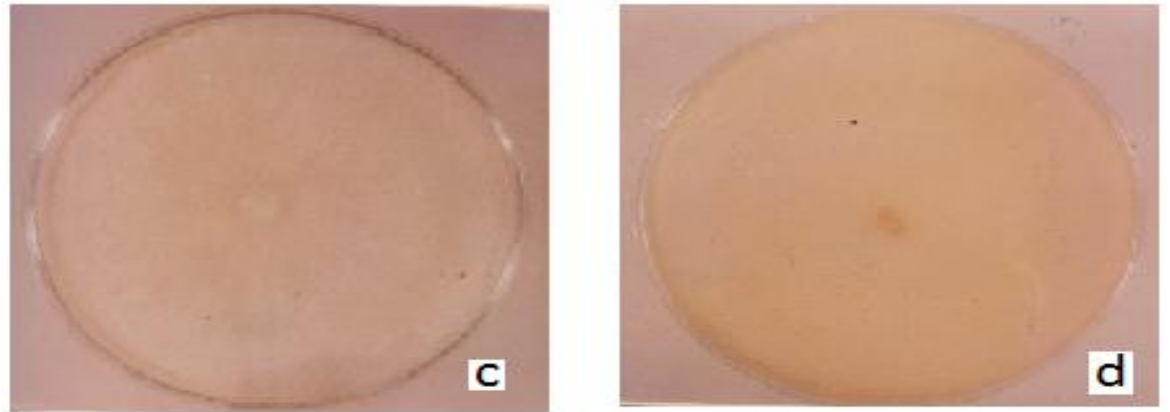
Tests for extracellular oxidasesBenzidinetest negative, brown rot on dead wood.

Distribution - recorded from India, SouthAfrica, Kenya, United State, Europe, Poland, North Central Asia, North America and North Africa cosmopolitan species. One specimen examined collected from karnala; RPO-4 on Garugapinnataand other specimens from pethSurgana RPO-30 Pongamiaglabra.

\section{Culture Characters:}

(Figure.4and Figure. 5)

Growth characters- growth moderate 45$50 \mathrm{~mm}$ in two weeks, entire plate covered in two weeks; Advancing zone hyphae white, appressed to raised, margin fimbriate to fringed, mat whitish becoming cottony to woolly; silky to cottony, crustose area developed, upper surface zonate; Reverse bleached to darkened as yellowish to brownish circular zones, at centre it is dark, odour none.

Tests for extracellular oxidase - are negative on gallic acid and tannic acid agar diffusion zones were none, for $\alpha$-ngapthol, Gauaicol and syringaldazine reaction were negative.

Hyphalcharecters - Advancing zone hyphae hyaline thin walled, much branched, septets with clamps 1.2-2.4 $\mu \mathrm{m}$ in diameter; Aerial hyphae hyaline, slightly thick walled, branched 1.5-3.2 $\mu \mathrm{m}$ in diameter, submerged hyphae hyaline to pale yellow, thin to thick walled, shortly branched $2.5-4.3 \mu \mathrm{m}$ in diameter, some are with terminal intercalary swellings up to $6.4 \mu \mathrm{m}$. Chlymadospores: present 11.5 x $4.1-6.4 \mu \mathrm{m}$
Species Culture code $\mathbf{7}, 12,13,20,21,22,28,29,30,(31), 37,39,44,45$, $46,48,51,52,53,54,80,85,89$.

Remarks - The species is a cosmopolitan species, common in temperate zoneup to the regions of Mediterranean climate. Ryvarden\& Johansen (1980) described it from East Africa and was also known from South Africa. The species is recorded for the first time from India and in the Western Ghats. It shows clear affinity with tropical African polypores.

\section{References}

Akhtar, M., Attridge. M.C., Myers, G.C., Kirk, T.K. and Blanchette, R.A. 1992. Biomechanical pulping of Loblolly Pine with different strains of the white rot fungus Ceriporiopsissubvermispoora.Toppi Journal:105-109.

Asiegbu FO, Nahalkova J, Li G, 2005. Pathogen -inducible cDNAs from the interaction of the root rot fungus Heterobasidionannosum with Scots pine (PinusSylvestris L.) Plant Science 268: 365-372.

Baldrian T, Gabriel J (2003). Lignocellulose degradation by Pleurotusostreatusin the presence of cadmium.FEMS Microbiol.Lett. 220:235-240.

Beneke, E.S. 1958. Laboratory Manual of Medical.Mycology. V+186, pp: Pl. IXIII.

Biotechnology 58: 582-594.

Ch. Ramesh and Manohar G. Pattar, 2009. Biodegradation of Pentachlorophenol by white rot fungi isolated from forests of Western Ghats of Karnataka India. Current trends in Biotechnology and Pharmacy, October-2009-3(4). Retrieved from http://www.pharmainfo.net/articles 
Cohen R, Persky L, Hadar Y, 2002. Biotechnological applications and potential of wood

conservation needs and management options. European journal of forest research 127: 1-22.

degrading mushrooms of the genus Pleurotus. Applied microbiology and

Eriksson, K.E.L., blanchette, R.A. and Ander P. 1990.Microbial and enzymatic Degradationof Wood and Wood components.Springer-Verlag, Berlin Heidelberg, 407p.

Gilbertson, R.L. and Ryvarden, L. 1986. North American polypores., Vol. 1, pp.433. Fungiflora, Oslo, Norway.

Hawksworth, D.L. 1991. The Fungal Dimension of Biodiversity: Magnitude, Significance and Conservation. Mycological research 95: 641-655.

Hawksworth, D.L., Sutton, B.C. and Ainsworth, G.L., 1983. Ainsworth and Bisbay's Dictionary of fungi. $7^{\text {th }}$ Edn. Kew, Commonwelth mycological Institute. 08, England, pp. 445.

Hintikka, J. and Laine, L. 1970. Notes on the detection of different types of decay in wood.MetsantJulk . 70(1) : $1-15$

Kaushik P. and Malik A., 2009. Fungal dye decolourization: Recent advances and future Potential. Environ Int., Vol. 35: 127-141.

Leonowicz, A., A. Matuszewska, J. Luterek, D. Ziegenhagen and M. WojtasWasilewska $e t \quad a l$., 1999. Biodegradation of lignin by white rot fungi.Fungal Genet. Biol., 27: $175-185$

Lonsdale D, Pautasso M, Holdenrieder O, 2008. Wood decaying fungi in the forest:

Martin, G.W. 1934. Three new Heterobasidiomycetes Mycologia $26(3): 261-265$.

Nobles, M.K. 1948.Studies in forest pathology. VI. Identification of cultures of wood- rotting fungi. Can. J. Res. Sect. C; 26 : 281-431.

Nobles, M.K. 1965.Identification of cultures of wood inhabiting Hymenomycetes. Can. J. Bot. 43 : 1097-1139.

Ofodile L.N., Uma N.U.,Attah L.E., Simmonds M.S.J., Popoola O.E., 2010. Cnemomorphological study and antimicrobial activity of DaedaleaQuercina.Acta SATECH 3(2): 102-107.

Overholts, L.O. 1953. The polyporaceae of the United States, Alaska and Canada. Univ. of Michigan Press, Ann. Arbor; Michigan, : 1-466.

Rayner, A.D.M. 1975. Fungal colonization of hard wood tree stumps. Ph.D. thesis, University of Cambridge.

Singer, R. 1982. The Agaricales in modern taxonomy. J. Cramer, Weinheim; $2^{\text {nd }}$ ed. : $1-915$

Stalpers, J.A. 1978. Identification of wood inhabiting Aphyllophorales in pure culture. Stud. Mycol. No. 16.

Turner, J.C., Skerker, P.S., Burns, B.J., Howard, J.C., Alonso, M.A. and Andres, J.L. (1992).Bleaching with enzymes instead of chlorine-mill trials.Tappi Journal:83-89.

\section{How to cite this article:}

Mulchand M. Rathod. 2016. A Study on Wood-Decaying Fungi from the Forests of Western Maharashtra, India. Int.J.Curr.Microbiol.App.Sci. 5(3): 520-527. doi: http://dx.doi.org/10.20546/ijcmas.2016.503.061 